\title{
Pineal Gland Cyst
}

National Cancer Institute

\section{Source}

National Cancer Institute. Pineal Gland Cyst. NCI Thesaurus. Code C9483.

A fluid filled sac within the pineal gland. It is usually an incidental finding of no real clinical significance. 